\title{
Radiation exposure in spine surgery using an image-guided system based on intraoperative cone-beam computed tomography: analysis of 107 consecutive cases
}

TO THE READERSHIP: An error appeared in the article by Costa et al. (Costa F, Tosi G, Attuati L, et al: Radiation exposure in spine surgery using an image-guided system based on intraoperative cone-beam computed tomography: analysis of 107 consecutive cases. J Neurosurg Spine 25:654-659, November 2016).

In the Results, the number of patients who underwent 2 intraoperative 3D scans was 98, not 99 . The corrected sentence is shown below.

Specifically, 1 scan was performed in 2 cases (in revision surgery as final control); in 98 cases 2 scans were performed ( 1 for navigation and 1 for final control); and in 7 cases 3 scans were completed. 2017.

The article has been corrected online as of January 13,

Francesco Costa, MD

Humanitas Clinical and Research Center, Rozzano, Milan, Italy

INCLUDE WHEN CITING

Published online January 13, 2017; DOI: 10.3171/2016.11.SPINE151139a.

(c)AANS, 2017 